\title{
Quantificaç̣̃o, Estado e participação social: potenciais heurísticos de um campo emergente
}

\section{Alexandre de Paiva Rio Camargo* (1) \\ Renato Sérgio de Lima** (1) Daniel Veloso Hirata**}

\section{Resumo}

O artigo apresenta as perspectivas de análise da sociologia da quantificação, realçando seu potencial para revisitar debates teóricos e questões empíricas que atravessam diferentes campos, com ênfase em violência e segurança pública, relações étnico-raciais, educação e movimentos sociais, temas dos artigos que compõem esse dossiê. Procura-se mapear seu aparecimento e ainda incipiente desenvolvimento no país e demonstrar como seu quadro de referência pode ser utilizado para tratar, sob nova angulação, alguns dos problemas centrais da sociedade brasileira, como a letalidade policial, a desigualdade racial e o sistema escolar seletivo e discriminatório. Examinam-se as formas contemporâneas de quantificação, seus efeitos sobre a agência social, seus pontos de contato e suas diferenças na promoção da racionalidade neoliberal, preocupação compartilhada pelas contribuições aqui reunidas e revisadas.

Palavras-chave: quantificação, Estado, neoliberalismo, participação social.

\footnotetext{
* Universidade Candido Mendes, Rio de Janeiro, RJ, Brasil.

** Fundação Getúlio Vargas, São Paulo, SP, Brasil.

*** Universidade Federal Fluminense, Rio de Janeiro, RJ, Brasil.
} 


\section{Quantification, State and social participation: heuristic possibilities for an emerging field}

\section{Abstract}

The article presents the analytical perspectives of the sociology of quantification, highlighting its potential to revisit theoretical debates and empirical issues that cross different fields, with an emphasis on violence and public security, ethnic-racial relations, education and social movements, which are subjects of the articles that compose this dossier. It seeks to map the appearance and still incipient development of the sociology of quantification in the country and demonstrate how its frame of reference can be used to address, under a new angle, some of the central problems of Brazilian society, such as police lethality, racial inequality and the selective and discriminatory school system. Contemporary forms of quantification, their effects on social agency, their points of contact and differences in the promotion of neoliberal rationality are examined, a concern shared by the contributions gathered and reviewed here.

Keywords: quantification, State, neoliberalism, social participation.

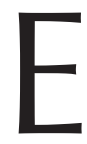

ste dossiê visa apresentar e fortalecer o emergente campo da sociologia da quantificação e suas perspectivas de análise no meio das ciências sociais brasileiras, em contribuições reunidas pela primeira vez em um número temático de uma revista em língua portuguesa. Nesta abordagem, as estatísticas importam não como método ou disciplina científica, mas como objetos culturais, artefatos que resultam de práticas sociais de classificação, registro e comparação de diferentes dimensões da realidade, desenvolvidas por instituições públicas e privadas.

Cifras, indicadores, índices, porcentagens, taxas e médias compõem o arsenal de prova e inferência das elites técnicas e científicas, extravasando o âmbito de aplicação para o qual foram inicialmente criados, para transformarem-se em categorias de percepção de múltiplos atores. Seu 
interesse para as ciências sociais reside no fato de transcenderem a linguagem puramente matemática e adquirirem caráter público. Trata-se de números que "recebem atenção midiática, traduzem interesses de diferentes grupos sociais, fornecem argumentos na resolução de controvérsias, estão sujeitos a apropriações diversas, prestam-se a usos eruditos e leigos, teóricos e práticos, sendo constantemente readaptados e ressignificados" (Daniel, 2013, p. 12).

Por serem públicos, esses números dão consistência a aspectos da realidade considerados socialmente problemáticos, mas que ainda se encontram difusos e controversos. Eles revelam dimensões opacas ou invisibilizadas da realidade e das bases sociais da política, essência mesma da sociologia política. O investimento em formas estatísticas permite estabilizar o que já está presente na sensibilidade coletiva, mas ainda não foi convencionado, dotando de dimensão e escala o que até então só podia ser percebido por palavras, isto é, qualitativamente. Por esta razão, a quantificação dos fatos sociais é parte importante - e, até recentemente, negligenciada - dos processos de reprodução e transformação das sociedades modernas.

Ao longo dos últimos quarenta anos, os estudos sobre a quantificação formaram-se a partir de obras de referência em diferentes áreas. De forma um tanto abreviada, apontamos algumas entre as principais delas. $\mathrm{Na}$ epistemologia histórica, destacam-se os trabalhos sobre o papel do cálculo de probabilidades e da noção de risco na formação das ciências humanas e na racionalização da vida social (Daston; Krüger; Heidelberger, 1987; Hacking, 1990; Porter, 1995). Os estudos em Ciência, Tecnologia e Sociedade trouxeram aportes sobre o papel dos números nas controvérsias públicas e na imposição da definição de situação pelos "centros de cálculo", como o laboratório (Latour, 1988; 2000). Já os estudos sobre identidade, raça e etnicidade revelaram o papel dos censos e suas classificações na instituição de novas categorias de pessoas (Anderson, 1988; Anderson, 1993; Kertzer; Ariel, 1999; Loveman, 2014). 
Por sua vez, as reflexões dos anglo-foucaultianos sobre os regimes de governo e gestão da população abordaram a estatística como uma tecnologia de produção de sujeitos "livres" e calculadores, ao fornecer aos atores normas e padrões para suas próprias aspirações e condutas (Foucault, 2008; 2009; Rose; Miller, 1992; Rose, 1999; Miller, 2001; Dean, 1999). Por fim, sob inspiração direta de Pierre Bourdieu (1979), o debate do pragmatismo francês sobre as convenções de equivalência e a pluralidade das lógicas de ação (Boltanski, 1982; Desrosières, Thévenot, 1988; Boltanski, Thévenot, 1991) forneceu um modelo para abordar o caráter simultaneamente real e convencional da estatística e sua correspondência com diferentes modalidades de crítica (Desrosières, 1993; Boltanski, 2009).

Em conjunto, essas obras colocaram em questão a performatividade dos números na vida pública e privada; seu uso como ferramenta de coordenação social; seus efeitos sobre a distribuição de recursos, conhecimentos e oportunidades; sua reatividade sobre as pessoas, transformando os modos como elas pensam e agem sobre si mesmas, sozinhas ou em relação com os outros. Afinal, a conversão de qualidades em quantidades cria novas coisas e novos nomes, tornando certas identidades mais reais do que outras. Um exemplo é a construção dos cadres, termo que designa executivos assalariados e que é fundamental para a estrutura ocupacional na França. Embora originado de um movimento de solidariedade entre engenheiros e administradores no final dos anos 1930, somente teve sua existência formalizada quando se tornou uma nomenclatura estatística nas análises de mobilidade e estratificação.

Este é apenas um caso da tendência mais geral apontada por Boltanski (1982) e Desrosières (1993) de que, para ganhar reconhecimento, os grupos têm interesse em institucionalizar estatisticamente categorias compatíveis com suas aspirações. Mais recentemente, assistimos processo semelhante na tentativa de alguns cientistas sociais franceses de introduzir a categoria "intelectuais precários", englobando diferentes profissionais culturais, cuja grandeza moral estaria afetada pela precarização do trabalho e pelo avanço de um modo de vida crescentemente utilitarista (Tasset, 2014). Os dois 
exemplos acima apontam para o potencial heurístico dos estudos sobre a quantificação na renovação do interesse e da abordagem em temas caros às sociologias do trabalho e da estratificação.

Outra frente importante aberta pela sociologia da quantificação diz respeito à iluminação do trabalho estatístico das agências públicas, como o INSEE, na França, o Census Bureau, nos Estados Unidos, ou o IBGE e o SEADE, no Brasil. Neles, o espaço para a criação de programas de trabalho e agendas de pesquisa está diretamente ligado aos microprocessos burocráticos e às redes de poder que determinam o que pode e o que deve fazer parte do rol de atenção das agências públicas de estatística, nas quais o domínio técnico ganha grande relevância. A negociação de um programa de pesquisas passa, nesse sentido, não só pelo convencimento de sua pertinência política, mas por sua viabilidade técnica, o que depende da solidez conceitual e das redes de uso que tornam as estatísticas estáveis e resistentes à crítica (Desrosières, 2008).

Mais do que isso, o repertório do conhecimento técnico-científico efetivamente disponível nessas agências se mostra determinante na incorporação de novos temas nas suas agendas de pesquisa, demandados por atores econômicos e movimentos sociais. Tal é o caso, por exemplo, das pressões pelo alargamento do conceito estritamente econômico de Produto Interno Bruto (PIB), que hoje passam pela inclusão do trabalho doméstico, da biodiversidade e de outras formas de riqueza compatíveis com o desenvolvimento social e sustentável. Isso ajuda a explicar por que as instituições que produzem estatísticas parecem mais refratárias a quantificar temáticas de maior fluidez, cujas bases legais e conceituais inexistem ou permanecem em disputa (Comte, 1995).

Para compreender os programas de trabalho das agências de estatística, é preciso analisar o embate de "verdades" profissionais, que preferem focar nas pesquisas primárias, cujas regras, técnicas e métodos podem ser inteiramente controladas (Lima, 2010). Dados gerados a partir de registros administrativos são vistos com enorme cautela e, com isso, deixados para um segundo plano - com exceção de alguns dados econômicos e sobre finanças 
públicas, que ajudam a compor e construir indicadores relevantes da agenda do IBGE, como as contas nacionais. Entretanto, as formas contemporâneas de objetivação da realidade impõem consideráveis desafios metodológicos à produção de conhecimento. Para Lima, novas tecnologias, aliadas a processos de compartimentalização e hiperespecialização do saber, geram cenários complexos - dados em quantidades cada vez maiores; informações fragmentadas e nem sempre passíveis de validação e/ou confirmação, como no exemplo da Internet e das fake news; comunicação instantânea, redes sociais, entre outros -, que não são passíveis de serem apreendidos apenas pelo uso das técnicas tradicionais de mensuração da realidade. Nesse processo, as agências públicas de estatísticas vêm-se, muitas vezes, sem referenciais sobre a agenda de temas contemplados num sistema nacional ou regional de estatísticas e, com isso, acabam reforçando posturas de insulamento institucional ou, mesmo, metodológico (Lima, 2010).

A sociologia da quantificação não apenas permite compreender os determinantes sociais desse insulamento, como mostra aos diferentes atores e organismos envolvidos no circuito de produção, circulação e tradução dos números que há limitações e escolhas implícitas em todos os procedimentos estatísticos, insistindo em que é impossível oferecer soluções técnicas a conflitos de interesse que não podem ser acomodados. Mais ainda, a sociologia da quantificação oferece aos produtores de informações estatísticas um saber reflexivo sobre os efeitos e condicionantes de suas práticas, o que traz a vantagem de ampliar sua legitimidade sociopolítica, sem prejuízo de sua credibilidade técnico-científica (Camargo, 2009).

Curiosamente, a primeira leva de trabalhos brasileiros que hoje se enquadrariam facilmente na sociologia da quantificação foi escrita por autores com atuação acadêmica e que, ao mesmo tempo, integraram ou dirigiram as principais agências de produção de dados do país. Suas preocupações com a divisão do trabalho estatístico refletiram essa inserção. Ao presidir o IBGE, Simon Schwartzman dedicou-se a pensar as traduções que têm lugar nas controvérsias estatísticas, levando em consideração a cultura profissional específica dos produtores de dados, pautada por regras 
e valores mistos da ciência e da burocracia, em uma abordagem em parte latouriana, e em parte mertoniana (Schwartzman, 1999). Inspirado por esse autor, Nelson Senra, pesquisador do IBGE, enfocou os produtores nos espaços institucionais, assinalando a importância de se compreender quem oferece as estatísticas e como esse processo é realizado. Sua obra examinou como as estatísticas são tensionadas pelo processo de distinção entre o que chamou de "tempo da oferta" e "tempo da demanda" das informações. Haveria aqui dois campos discursivos antagônicos, que disputam um objeto por sua capacidade de ser contado ou, ao contrário, por suas individualidades intrínsecas, ou seja, conflitos sobre o que contar e quantificar, que não podem ser completamente acomodados (Senra, 2005). Já a tese de doutorado de Renato Sergio de Lima (2005), que foi chefe da divisão de estudos socioeconômicos do SEADE, mostrou como a pressão pelo controle público das ações policiais na redemocratização não resultou na coordenação entre produtores e usuários das estatísticas criminais, levando a um movimento simultâneo e paradoxal de crescimento dos estoques de dados gerados, de um lado, e o reforço da opacidade dos números no desenho das políticas de segurança pública, de outro.

Mais recentemente, a proliferação das formas contemporâneas de quantificação, marcadas pelo advento da "governamentalidade algorítmica" (Rouvroy, 2015) e pela difusão do benchmarking no Estado e no serviço público (Bruno; Didier, 2013), ampliaram o interesse dos cientistas sociais para além das estatísticas oficiais, inclusive no Brasil. Diferentes iniciativas têm procurado demonstrar que a sociologia da quantificação pode ser utilizada para tratar, sob nova angulação, alguns dos problemas centrais da sociedade brasileira. Em diálogo com a sociologia histórica, a tese de doutorado de Alexandre de Paiva Rio Camargo (2016) examinou a lenta construção da autoridade dos números no Brasil e as condições de sua conversão em referente para a ação coletiva. Um processo que, para o autor, se estende entre o Império, quando as estatísticas administrativas predominavam sobre as populacionais, refletindo a racionalidade do Estado Territorial, e a Primeira República, quando se desenha a interdependência 
sanitária e social do país, dando origem a um novo regime de ação sobre a população.

Em seguida, o dossiê temático "quantificar no Brasil", resultado de aproximações de pesquisadores brasileiros e franceses interessados no tema, foi organizado por Emmanuel Didier para a revista Statistique et Société (Didier, 2019). De formas variadas, o coletivo de pesquisadores reunidos procurou mostrar, seguindo as pistas seminais de Alain Desrosières, mas também de Theodore Porter, como as estatísticas são, ao mesmo tempo, um instrumento de prova e de governo (Desrosières, 2008). Desta tensão intrínseca à "ciência do Estado", é possível, por um lado, entender como pode ser problemático quantificar favelas (Motta, 2019), como mercados ilegais são produzidos pelos números como problema a ser combatido em alianças entre elites políticas econômicas (Rabossi, 2019), a generalização da vigilância preditiva e sua promoção pela quantificação do tempo de intervenção (Cardoso, 2019), mas também como a objetificação de tiroteios e operações policiais pela sociedade civil cria novos debates no espaço público, antes ocultados pela ausência de números (Hirata; Couto; Grillo; Olliveira, 2019). As articulações, portanto, do uso dos números como instrumentos de prova e de governo, assim como diferentes possibilidades de se pensar o atravessamento entre Estado e sociedade, permitem explorar através de uma perspectiva renovada, temas clássicos das ciências sociais e questões públicas relevantes.

Por um lado, os atravessamentos constitutivos da tensão da estatística como instrumentos de prova e de governo, incluindo as novas formas de quantificação que vão estabelecendo a legibilidade e a instrumentação do governo de territórios e populações, colocam em evidência um modelo de racionalidade contemporânea baseada no risco, na vigilância e na tecnologia. As escolhas políticas são apresentadas como resultados de técnicas analíticas padronizadas; os serviços públicos são comodificados e monitorados pela capacidade de satisfazer uma clientela formada por cidadãos, em uma relação que se reduz à eficiência e à utilidade, esvaziada do princípio de universalidade e proteção que até então caracterizava o moderno Estado- 
nação. Por outro lado, intensas mobilizações na sociedade civil se fazem por meio de números, de indicadores e de formas de classificação que tensionam esta legibilidade padronizada e vão pontuando os limites das violações dos direitos civis.

No campo da segurança pública, por exemplo, a dificuldade não está na produção de dados criminais em si, que existem no Brasil desde 1871, mas na forma como eles são compilados e como são mobilizados para justificar regimes de verdade que visam manter práticas retroalimentadoras da violência. Ou seja, ao se optar seja por somar as mortes decorrentes de intervenção policial no total dos homicídios registrados e/ou, em sentido contrário, ao se optar por excluir dessa soma tais mortes há, ao fim e ao cabo, uma enorme disputa acerca do que significa lei, ordem e segurança pública. O embate desloca-se do tempo de produção para o tempo de uso, na ideia de que há consenso de que os números devem ser gerados, mas há conflito sobre o que eles traduzem e quem pode ter acesso aos detalhes que permitiriam análises mais amplas do problema (Lima, 2005).

Este embate se reflete em diversos níveis, como, por exemplo, nos estímulos à atividade policial feitos pelos governos do Estado do Rio de Janeiro. Desde 2009, o Instituto de Segurança Pública (ISP/RJ) organiza os dados para o "Sistema de Metas e Acompanhamento de Resultados", baseado nos "Indicadores Estratégicos de Criminalidade". A estratégia gerencial, concebida por consultorias privadas, é construir indicadores de performance capazes de induzir a ação dos profissionais da área de segurança pública em uma certa direção. Sobre esse ponto, a profusão de dados de algumas das grandes ONG's e think tanks nacionais e internacionais presentes do Rio de Janeiro também buscam criar parâmetros avaliativos de políticas públicas, dos regimes de eficácia de ações e programas, por meio de indicadores de performance, avaliação e rankings, típicos do benchmarking (Bruno; Didier, 2013).

Pode-se dizer que a introdução dos indicadores de performance foi um avanço considerável em relação à chamada "premiação por bravura" (mais conhecida como "gratificação faroeste"), que, entre 1995 e 1998, 
contabilizou os homicídios decorrentes de intervenção policial como "produtividade" a ser bonificada, fazendo assim aumentar no período a letalidade da ação policial (Cano, 1997). Apesar do avanço, parece haver um problema não apenas em relação aos critérios em que repousam os indicadores de performance, mas também na própria utilização dos indicadores como instrumentos de governo. Isso se deve ao conhecido problema do gaming (Bevan; Hood, 2006), o jogo estratégico dos atores sobre tais indicadores de performance e sistemas de metas, que procura controlar e dirigir suas ações. Novamente, o caso do Rio de Janeiro, quanto a esse aspecto, é exemplar: quando a letalidade policial emergiu como questão pública, o número de pessoas desaparecidas passou a crescer na mesma proporção em que decresciam os registros de "auto de resistência" (Araújo, 2014).

Ao lado da difusão do benchmarking, seus rankings e avaliações de performance, as métricas da governamentalidade neoliberal impõem outros desafios à esfera pública e à democracia, os quais têm merecido atenção dos cientistas sociais. A quantificação algorítmica encontra-se na aplicação de modelos matemáticos à gestão da população. Nesse caso, a circulação massiva de microdados permite acessar territórios, grupos, instituições, mercados e países em frações de segundos. Um saber automatizado emerge das correlações de informações seriadas não previamente selecionadas, não hierarquizadas e altamente heterogêneas, reduzindo a intervenção humana e dispensando hipóteses e convenções sobre o mundo social (Rouvroy, 2014). Em forte contraste com a estatística oficial, os big data se caracterizam pela automação em relação às convenções, escapando às disputas de uma esfera pública que se torna opaca, balizando inúmeras decisões de governos e empresas que esvaziam os canais de deliberação democrática.

Em diálogo com a sociologia digital, mas demarcando a sua contribuição, a sociologia da quantificação chama atenção para a racionalidade política que reúne ou separa as diferentes formas de quantificar no neoliberalismo. No caso dos algoritmos e do benchmarking, ambos se baseiam na coleta, 
agregação e análise descentralizada de dados, com o fim de modelizar, antecipar e afetar comportamentos. Trata-se de uma característica distintiva da quantificação no neoliberalismo, que promove a interação entre agentes sociais e tecnologias autônomas para torná-los sujeitos da sua própria observação e classificação, monitores de suas sociabilidades (Camargo, 2021).

Não à toa, os movimentos sociais nunca atuaram tanto com as estatísticas como na atualidade, como mostram a forte politização das categorias raciais e a reivindicação de quantificar espaços até pouco tempo não-comensuráveis, como a biodiversidade, as formas de trabalho nãoremunerado, a participação no consumo cultural, a desigualdade racial e a violência de gênero. Trata-se de domínios considerados problemáticos, que são progressivamente objetivados e construídos pelos números como problemas públicos, o que permite transformar as sensibilidades coletivas em relação a eles, e dar formas institucionais a experiências e aspirações até então fragmentadas e difusas, concorrendo assim diretamente para a mudança social.

As contribuições aqui reunidas abordam as condições de produção e os modos de uso das estatísticas oficiais e demais formas contemporâneas de quantificação da realidade, especialmente o benchmarking e a avaliação de performances por indicadores e rankings, dispositivos de governo que retroagem sobre os atores e afetam a constituição das subjetividades. Nesta leitura, interessa compreender a estatística como tecnologia de transferência do risco para os indivíduos, por meio da qual os comportamentos nãoeconômicos - como a criminalidade, a atividade policial, as decisões judiciais, a vida familiar e as patologias sociais - passam a ser lidos pela chave analítica da economia, por meio da quantificação das atividades humanas.

Ao mesmo tempo, outra perspectiva é igualmente necessária, pois as estatísticas não são e nem sempre foram armas exclusivas dos poderosos, permanecendo inesgotável seu potencial para desafiar consensos e repolitizar as relações sociais. Embora seja longa a tradição de uso das estatísticas para garantir demandas por direitos, como no caso mais explícito das indexações 
do salário e do custo de vida nas reivindicações sindicais, algumas formas de intervir com números são bastante recentes, especificamente destinadas a atacar os métodos de dominação característicos da governamentalidade neoliberal. Importa aqui abordar a resistência dos movimentos sociais ao recorrerem aos números contra os poderes institucionalizados, as desigualdades e o modelo gerencial de gestão. Os números revestem-se de usos políticos e, cada vez mais, são problematizados e/ou disputados, exigindo uma constante vigilância epistemológica sobre seus métodos e conceitos para que não sejam reduzidos a meros recursos retóricos na construção de narrativas típicas da era da pós-verdade e das fake news.

Nesse sentido, o dossiê pretende debater as transformações do Estado e as modalidades de participação social, do ponto de vista de sua ancoragem nos números públicos e da produtividade política da estatística, com o fim de descortinar novas possibilidades de crítica do presente e de governo do futuro. Como ponto de partida, o artigo "Os estudos sociais da quantificação e suas implicações na sociologia", de Alexandre de Paiva Rio Camargo e Claudia Daniel, busca reconstruir as origens do campo e suas transformações ao longo dos últimos anos, chamando atenção para as relações entre a sociologia da quantificação, a socio-história da estatística e, em menor medida, a antropologia dos números. O objetivo do autor e da autora é estimular um programa de trabalho pelo qual a sociologia deveria ampliar sua atenção para as operações e os regimes de quantificação nas sociedades contemporâneas. E, para demonstrar essa intenção, fazem uma ampla revisão da literatura e examinam as contribuições acumuladas nesta literatura que dialogam diretamente com as questões centrais da sociologia, como o problema dos fundamentos da ordem social e da autoridade política; os processos de diferenciação social e configuração de subjetividades; a crítica e a agência social transformadora. Ao final, fica o apelo por um programa de investigação que, oriundo do método sociológico, evidencie os efeitos produzidos pelos dispositivos de quantificação entre os diferentes grupos sociais, e revele os modos como as relações de poder operam através da opacidade dos números. 
Estatativismo é um neologismo criado por Isabelle Bruno e Emmanuel Didier para nomear o crescente campo de práticas de ativismo baseados em números em diversos lugares do mundo. Se, em trabalhos anteriores, os autores buscaram compreender, na esteira do pensamento e do trabalho conjunto com Alain Desrosières, o tipo específico de quantificação próprio do governo neoliberal (Desrosières, 2014), mais recentemente procuraram iluminar como as diferentes formas de ação através dos números pontuam um campo de resistência. No artigo que compõe este dossiê fica bastante claro que essa oposição é matizada nas oposições e relações entre Estado e sociedade. Iniciando a sua tipologia do estatativismo, os autores identificam práticas que antecedem o governo neoliberal ou se encontram situadas nele mesmo, portanto com amplitude crítica variável, radical ou reformista - tomando esta distinção de Luc Boltanski. Também mostram que o contornamento das regras de condução das condutas imposto pelo governo neoliberal é feito por uma série de estratégias de resistência aos indicadores de performance, metas e rankings, típicos do benckmarking, como no caso dos policiais submetidos ao famoso Compstat, parte do projeto de "tolerância zero" de Nova York. Em seguida, descrevem a construção das novas categorias coletivas, como aquelas associadas ao trabalho precário de artistas e intelectuais em suas demandas por direitos sociais e trabalhistas. E, por fim, passam em revista os números públicos alternativos, como é o caso citado da quantificação de tiroteios e operações policiais no Rio de Janeiro, que possibilitam colocar em debate questões que antes não estavam presentes. Como dizem os autores, não sem humor, "outros números são possíveis", ou outros números ajudam a instituir outros possíveis.

Em "A política de um cenário de dados transformado: estatísticas etnorraciais no Brasil em perspectiva comparativa regional", Mara Loveman examina o protagonismo regional do Brasil na superação da cegueira étnico-racial que caracterizava os censos latino-americanos antes da virada do século. Após traçar um panorama histórico que reserva um lugar de destaque ao censo na construção da ficção científico-demográfica do branqueamento, a autora aborda a crescente politização da produção dos 
números, a partir dos anos 1980, promovida pela coalizão de ativistas, cientistas sociais e organizações internacionais, que pressionou as agências nacionais de estatística a se engajarem abertamente na coleta de dados etnorraciais. A experiência brasileira é analisada em detalhe por servir de modelo a outros países da região, como Colômbia, Bolívia e Chile, onde a composição de forças forjada pelo alinhamento epistemológico e político não teve, todavia, o mesmo impacto, devido a razões examinadas pelo artigo. Uma vez institucionalizada, a classificação étnico-racial transformou a política em toda a região, dando origem a novos espaços para a participação dos grupos de cor, novas subjetividades, impulsionadas por campanhas midiáticas que encorajaram o reconhecimento da herança africana e a consequente mudança na autoidentificação, e novas demandas políticas.

Esse quadro produziu novos debates e tensões, como a discrepância entre as categorias oficiais, cuja abrangência é considerada ampla demais, e os objetivos das políticas de combate à desigualdade, de que resultam distorções entre os beneficiários. Por sua vez, essas tensões estimulam a eclosão de controvérsias e subjetividades reativas, que se configuram em oposição à categorização oficial e emergem com o discurso nacionalista da nova direita, que insiste na ressubordinação das identidades etnorraciais a uma identidade atávica brasileira. Na conclusão, a autora propõe uma contribuição teórica, uma alternativa à imagem de "efeito circular" (looping effect) cunhada por lan Hacking (1986), ao se referir à recursividade das classificações estatísticas sobre a realidade que descrevem. À luz das transformações no terreno político, sugere a metáfora de um "efeito espiral" para dar conta das consequências imprevisíveis da criação e dos modos de uso dos dados etnorraciais, que podem ser tanto positivos quanto negativos para os objetivos daqueles que os produzem.

Na sequência, o artigo de Samira Bueno, Renato Sérgio de Lima e Arthur Trindade, "Quando o Estado mata: desafios para medir crimes contra a vida cometidos por policiais", destaca de forma muito clara e situada historicamente a diferença e os descompassos entre a produção de dados estatísticos oficiais e sua utilização como forma de leitura dos instrumentos da 
ação pública. Refletindo sobre a maneira pela qual os homicídios cometidos por policiais foram sendo classificados no Brasil, os autores problematizam esta interface entre estatísticas e ação pública, normalmente tomada como auto evidente. Para tanto, comparam os dados provenientes da área da saúde pública e do sistema de justiça criminal, cujas bases epistêmicas (médicoepidemiológica e jurídico-policial) orientam diferentes taxinomias, nem completamente distintas e nem absolutamente compatíveis; destacam as disputas pelas nomenclaturas e classificações sobre os homicídios cometidos por policiais como parte das tensões políticas que configuram o campo conflitivo do tema; e apontam dificuldades de construção de equivalências nos espaços regional, nacional e internacional. Ao fim e ao cabo, argumentam os autores, as classificações sobre os homicídios cometidos por policiais, acabam por delimitar o campo dos sentidos que tomam o debate público, de um lado sobre a questão dos homicídios em geral, em que pesam cada vez mais os homicídios praticados por policiais, como também os perversos processos de inversão que fazem com que vítimas da violência de Estado se transformem em suspeitos ou culpados.

Natália de Lacerda Gil fecha o dossiê com o artigo "A quantificação da qualidade: algumas considerações sobre os índices de reprovação escolar no Brasil". Inserindo-se na literatura sobre o papel dos rankings na construção da excelência (Bruno; Didier, 2013; Espeland; Sauder, 2016), a autora questiona o que se entende por qualidade na educação, implícita nas escolhas metodológicas e nos procedimentos de quantificação do desempenho escolar, enfatizando a importância de analisar a imagem de eficiência que os índices buscam mensurar e promover. Com este fim, o artigo relaciona a busca pela progressiva democratização da escolarização elementar à produção sistemática das estatísticas escolares, iniciada na Era Vargas, quando a apreensão da reprovação passa a se apresentar como problema político-educacional do país. Partindo desse marco, examina-se a formação de uma tradição caracterizada pela coexistência entre o foco no fraco desempenho escolar dos alunos e as críticas aos altos índices de reprovação, repudiados por causarem seletividade e exclusão. Em seguida, 
discute-se a construção do Índice de Desenvolvimento da Educação Básica e sua articulação com a política neoliberal de maximização da eficiência, que desloca a noção de qualidade como "equidade" para a proposição de qualidade como "excelência". A autora conclui que a longa tradição de avaliação da qualidade do ensino pela medição do que sabem os alunos se mantém no IDEB, que assim amplia, ao invés de corrigir, as distorções de uma cultura escolar seletiva e discriminatória.

As obras acima revisadas e a variedade de objetos e temas abordados por este dossiê demonstram o potencial dos estudos da quantificação para renovar debates teóricos e questões empíricas que atravessam diferentes sociologias temáticas, com ênfase na violência e na segurança pública, nas relações étnico-raciais, na educação e nos movimentos sociais. Sem nenhuma pretensão à exaustividade, procuramos recortar o emergente campo da sociologia da quantificação, de maneira a apresentar suas principais referências, mapear seu surgimento e ainda incipiente desenvolvimento no país, e relacionar alguns problemas concretos do Brasil contemporâneo que se tornam enriquecidos por essa perspectiva analítica. Possivelmente, alguns nomes e obras ficaram de fora de nossa revisão, refletindo o caráter disperso do campo entre nós, razão pela qual a imagem de uma trilha da produção intelectual nos parece mais pertinente que a de mapa. Ao mesmo tempo, o dossiê vem refletir e atender a presença crescente da quantificação na pós-graduação brasileira, manifesta no volume de trabalhos que têm sido apresentados nos congressos da SBS e nos encontros da ANPOCS. Novas pesquisas e jovens pesquisadores prometem reforçar a vocação da quantificação como uma conversa vibrante que cruza diferentes campos, ampliando sua caixa de ferramentas para a compreensão da realidade.

De forma inusitada, o momento singularmente difícil que o país atravessa também aponta nessa mesma direção. A pandemia de Covid-19 que assola o mundo, reservando uma sorte ainda pior ao Brasil, faz aflorar o papel das formas de quantificar na gestão e na vivência da crise como experiência coletiva. Os modelos preditivos mirando o "achatamento da curva" (Motta, 2020), as cifras de casos e mortes escalonando as decisões 
sobre lockdown, reabertura e isolamento, as taxas de ocupação de leitos em UTIs, os números redondos pontuando o luto coletivo são todos marcos de construção da temporalidade e de alongamento de um presente acossado entre a cisão radical com o passado não-anômalo e o céu imaginário de um futuro sem crise. Mais do que nunca, salta aos olhos o poder mobilizador dos números como referente comum e sua retroação sobre os atores sociais.

De igual modo, o esvaziamento inicial e o virtual cancelamento do censo de 2020 arriscam mergulhar o país no obscurantismo e na ignorância dos aspectos mais básicos de qualquer política populacional. Ao mesmo tempo, os cortes e o desmantelamento do censo apontam para a centralidade das estatísticas na construção das diferentes formas de desigualdade - regional, econômica, racial, sexual e de gênero -, colocando em inédita evidência um front fundamental da luta social. De um lado, a reinvindicação do que deve e importa ser contado, feita pelos movimentos sociais; de outro, a destruição da medida da desigualdade como estratégia de solapamento da verdade e negação da realidade, compartilhada pela nova direita global. Tal quadro revela que os números públicos assumem protagonismo não apenas quanto às dimensões estruturantes da vida social, como também nas disputas mais essenciais sobre a agenda política.

Encerramos com um agradecimento às autoras e aos autores que aceitaram integrar esse projeto. Agradecemos, ainda, a Jalcione Almeida, editor-chefe de Sociologias, por acolher nossa proposta de fomentar o debate sociológico em um campo promissor e tão relevante, porém ainda carente de investigações e espaços de reflexão no Brasil. A Victor Alves Mourão, Eugênia Motta e Antônio Paulino, agradecemos as interlocuções em diferentes momentos e o apoio a iniciativas que ajudaram a tornar possível este dossiê. Aos pareceristas anônimos que avaliaram os artigos deixamos nosso reconhecimento. E convidamos à leitura, desejando que inspire diálogos disciplinares. 
Alexandre de Paiva Rio Camargo é Professor adjunto do Programa de Pós-Graduação em Sociologia Política da Universidade Candido Mendes.

$\triangle$ alexandre.camargo.2009@gmail.com

Renato Sérgio de Lima é Professor do Departamento de Gestão Pública da Fundação Getúlio Vargas de São Paulo, Diretor-Presidente do Fórum Brasileiro de Segurança Pública.

$\bowtie$ renato.lima@forumseguranca.org.br

Daniel Veloso Hirata é Professor adjunto do Programa de Pós-Graduação em Sociologia da Universidade Federal Fluminense e pesquisador 2 do CNPq.

$\bowtie$ velosohirata@gmail.com

\section{Referências}

1. ANDERSON, Benedict. Comunidades imaginadas: reflexões sobre a origem e a difusão do nacionalismo. São Paulo: Cia das Letras, 1993.

2. ANDERSON, Margo. The American census: a social history. New Haven: Yale University Press, 1988.

3. ARAÚJO, F. Das técnicas de fazer desaparecer corpos. Rio de Janeiro: Lamparina/Faperj, 2014.

4. BEVAN, G; HOOD, C. What's measured is what matters. Targets and gaming in the English public health care system. Public Administration, v. 84, n. 3, p. 517-538, 2006.

5. BRUNO, Isabelle; DIDIER, Emmanuel. Benchmarking: L'État sous pression statistique. Paris: La Découverte, 2013.

6. BRUNO, Isabelle; DIDIER, Emmanuel; PRÉVIEUX, Julien (orgs.). Statactivisme: Comment lutter avec des nombres. Paris: La Découverte, 2014.

7. BOLTANSKI, Luc. De la critique : précis de sociologie de l'émancipation. Paris: Gallimard, 2009.

8. BOLTANSKI, Luc. Les cadres : la formation d'un groupe social. Paris: Éditions de Minuit, 1982.

9. BOLTANSKI, Luć; THÉVENOT, Laurent. De la justification : les économies de la grandeur. Paris: Éditions Gallimard, 1991.

10. BOURDIEU, Pierre. La distinction : critique sociale du jugement. Paris: Éditions de Minuit, 1979.

11. CAMARGO, Alexandre de P. R. Estado, quantificação e agência: uma análise genealógica. DADOS - Revista de Ciências Sociais, v. 65, n. 3, 2021, no prelo. 
12. CAMARGO, Alexandre de P. R. A construção da medida comum: estatística e política de população no Império e na Primeira República. Tese (Doutorado em Sociologia). Instituto de Estudos Sociais e Políticos, Universidade do Estado do Rio de Janeiro, Rio de Janeiro, 2016.

13. CAMARGO, Alexandre de P. R. Sociologia das estatísticas: possibilidades de um novo campo de investigação. História, Ciências, Saúde-Manguinhos, v. 16, n. 4, p. 903-925, 2009.

14. CANO, Ignácio. Letalidade da ação policial no Rio de Janeiro. Rio de Janeiro: ISER. 1997.

15. CARDOSO, Bruno. Benchmarking et sécurité à Rio de Janeiro. Statistique et Société, v. 7, n. 1, p. 25-30, 2019.

16. COMTE, Maurice. A fluidez e a rigidez. In: BESSON, Jean-Louis (org.). A ilusão das estatísticas. São Paulo: Unesp, 1995. p. 185-198.

17. DANIEL, Claudia. Números públicos: las estadísticas en Argentina (19902013). Buenos Aires: Fondo de Cultura Económica, 2013.

18. DASTON, Lorraine; KRÜGER, Lorenz; HEIDELBERGER, Michel (orgs.). The probabilistic revolution. Cambridge, Massachusetts: MIT press, 1987.

19. DEAN, Mitchell. Governmentality: power and rule in modern society. Londres: Sage, 1999.

20. DESROSIÈRES, Alain. La politique des grands nombres : histoire de la raison statistique. Paris: La Découverte, 1993.

21. DESROSIÈRES, Alain. Prouver et gouverner : une analyse politique des statistiques publiques. Paris: La Découverte, 2014.

22. DESROSIÈRES, Alain. Pour une sociologie historique de la quantification. Paris : Presses de L'École de Mines, 2008.

23. DESROSIÈRES, Alain; THÉVENOT, Laurent. Les catégories socioprofessionnelles. Paris: La Découverte, 1988.

24. DIDIER, Emmanuel. Éditorial. Statistique et Société, v. 7, n. 1, p. 7-8, 2019.

25. ESPELAND, Wendy; SAUDER, Michel. Engines of anxiety: academic rankings, reputation and accountability. Nova York: Russel Sage Foundation, 2016.

26. FOUCAULT, Michel. O nascimento da biopolítica. São Paulo: Martins Fontes, 2009.

27. FOUCAULT, Michel. Segurança, território, população. São Paulo: Martins Fontes, 2008.

28. HACKING, Ian. The taming of chance. Cambridge: Cambridge University Press, 1990. 
29. HACKING, lan. Making Up People. In: HELLER, Thomas; SOSNA, Morton; WELLBERY, David (orgs). Reconstructing Individualism: autonomy, individuality, and the self in western thought. Stanford: Stanford University Press, 1986, p. 222236.

30. HIRATA, Daniel; COUTO, Maria Isabel; GRILLO, Carolina; OLLIVEIRA, Cecília. Échanges de tirs : La production de données sur la violence armée dans des opérations de police à Rio de Janeiro. Statistique et Société, v. 7, n. 1, p. 31-40, 2019.

31. KERTZER, David; ARIEL, Dominique (eds.). Census and identity: the politics of race, ethnicity and language in national censuses. Nova York: Cambridge University Press, 2002.

32. LATOUR, Bruno. Ciência em ação: como seguir cientistas e engenheiros sociedade afora. São Paulo: Editora Unnesp, 2000.

33. LATOUR, Bruno. The Pasteurization of France. Cambridge: Harvard University Press, 1988.

34. LIMA, Renato Sérgio de. Sociologia, sínteses teóricas e a conformação de uma agenda de pesquisa sobre estatísticas públicas. In: SENRA, Nelson de Castro; CAMARGO, Alexandre de Paiva Rio (orgs.). Estatísticas nas Américas: por uma agenda de estudos históricos comparados. Rio de Janeiro: IBGE, 2010.

35. LIMA, Renato Sérgio de. Contando crimes e criminosos em São Paulo: uma sociologia das estatísticas produzidas e utilizadas entre 1871 e 2000. Tese (Doutorado em Sociologia). Faculdade de Filosofia, Letras e Ciências Humanas. Universidade de São Paulo, São Paulo, 2005.

36. LOVEMAN, Mara. National colors: racial classification and the State in Latin America. Oxford: Oxford University Press, 2014.

37. MILLER, Peter. Governing by numbers: Why calculative practices matter. Social Research, v. 68, n. 2, p. 379-396, 2001.

38. MOTTA, Eugênia. Les favelas : normalité et subnormalité dans le recensement national brésilien. Statistique et Société, v. 7, n. 1, p. 9-15, 2019.

39. MOTTA, Eugênia. "Achatar a curva": estética, topografia e moralidade da pandemia. Blog DADOS [publicado em 29/05]. 2020. Disponível em: http:// dados.iesp.uerj.br/estetica-da-pandemia/.

40. PORTER, Theodore. Trust in numbers: The pursuit of objectivity in science and public life. Princeton: Princeton University Press, 1995.

41. RABOSSI, Fernando. La contrabande au Brésil. Statistique et Société, v. 7 , n. 1, p. 17-23, 2019.

42. ROSE, Nikolas. Powers of freedom: reframing political thought. Cambridge: Cambridge University Press, 1999. 
43. ROSE, Nikolas; MILLER, Peter. Political power beyond the state: problematics of government. British Journal of Sociology, v. 43, n. 2, p. 172-205, 1992.

44. ROUVROY, Antoinette. Governamentalidade algorítmica e perspectivas de emancipação: o díspar como condição de individuação pela relação? Revista Eco-pós, v. 18, n. 2, p. 35-56, 2015.

45. ROUVROY, Antoinette. BigData: de nouveaux outils à combiner aux savoirs établis et à encadrer par la délibération publique. Statistique et Société, v. 2, n. 4, pp. 33-41, 2014.

46. SCHWARTZMAN, Simon. Legitimacy, controversies and translations in public statistics. Science, Technology \& Society, v. 4, n. 1, p. 1-34, 1999.

47. SENRA, Nelson. O saber e o poder das estatísticas: uma história das relações dos estaticistas com os Estados nacionais e com as ciências. Rio de Janeiro: IBGE, 2005.

48. TASSET, Cyprien. Les « intellos-précaires » et la classe créative : le recours à la quantification dans deux projets concurrents de regroupement social. In: BRUNO, Isabelle; DIDIER, Emmanuel; PRÉVIEUX, Julien. Statactivisme : commment lutter avec des nombres. Paris: La Découverte, 2014.

Recebido em: 14 abr. 2021. Aprovado em: 20 abr. 2021. 